\title{
O INCA GARCILASO DE LA VEGA E SEU TRÂNSITO ENTRE A COLÔNIA E A METRÓPOLE: REVISIONISMO HISTÓRICO E LITERÁRIO
}

\author{
Ximena Antonia Diaz Merino* \\ Universidade Federal Rural do Rio de Janeiro
}

\begin{abstract}
Resumo: Os primeiros textos literários coloniais de autoria indígena e mestiça foram publicados na América hispânica no século XVII. Primeiramente foi publicado o livro intitulado Comentarios Reales de los Incas (1609) escrito pelo mestiço peruano Inca Garcilaso de la Vega (1539-1616), e em 1615 foi publicada a Nueva corónica y buen gobierno de autoria do cronista indígena Felipe Guaman Poma de Ayala (1534-1615). Essas obras constituem parte importante do corpus literário colonial, pois se situam nas denominadas zonas de contacto (PRATT, 2010, p. 31). Esses textos coloniais escritos por mestiços ou indígenas apresentam um relato oposto ao desenvolvido pelos cronistas europeus no que se refere à representação do indígena, e revelam uma versão pessoal e diferente da história desses povos. Dentro desse contexto, a obra do Inca Garcilaso de la Vega pode ser considerada uma das primeiras fontes escritas por um mestiço que enfrentou a história oficial da conquista. O Inca Garcilaso participou ativamente na construção e narração de sua própria história, acabando com a posição secundaria e passiva que lhe conferiam os cronistas espanhóis.
\end{abstract}

Palavras-chave: Literatura pós-colonial. Revisionismo histórico. Descolonização cultural.

\begin{abstract}
Habiendo de tratar del nuevo mundo parece que fuera justo, conforme a la común costumbre de los escritores, tratar aquí al principio, si el mundo es uno solo o si hay muchos mundos.[...] que no hay más que un mundo. Y aunque llamamos 'mundo viejo' y 'mundo nuevo' es por haberse descubierto aquel nuevamente para nosotros y no porque sean dos, sino todo uno. (GARCILASO DE LA VEGA, 2015a, Tomo II, p. 19).
\end{abstract}

Es evidente que el fin que persigue el gran mestizo [Inca Garcilaso] es el de reivindicar a los indígenas del Perú, respecto de los injustos reproches de que eran objeto por otros cronistas. Es obra de madurez, escrita en estilo brillante y conciso

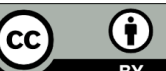

Esta obra está licenciada sob uma Creative Commons - Atribuição 4.0

\footnotetext{
* Possui Estágio Pós-doutoral em Literatura e História pela Universidade do Estado do Rio de Janeiro/UERJ (2017). Doutora e Mestre em Letras Neolatinas opção Literaturas Hispânicas pela Universidade Federal do Rio de Janeiro/UFRJ. Atualmente é Professora Adjunta de Culturas e Literaturas Hispânicas do Instituto Multidisciplinar da Universidade Federal Rural do Rio de Janeiro/UFRRJ. E-mail: ximenadm2@gmail.com.
} 


\title{
[‥]. (BLIXEN, 1990).
}

Os primeiros textos literários coloniais de autoria indígena e mestiça foram publicados na América hispânica no século XVII. Primeiramente foi publicado o livro intitulado Comentarios Reales (1609) escrito pelo mestiço peruano Inca Garcilaso de la Vega (1539-1616), e em 1615 foi publicada a Nueva corónica y buen gobierno de autoria do cronista indígena Felipe Guaman Poma de Ayala (1534-1615). Essas obras constituem parte importante do corpus literário colonial, pois se situam nas denominadas zonas de contacto, ou seja, nos "[...] espacios sociales en que culturas dispares se encuentran, chocan y se enfrentan, a menudo dentro de relaciones altamente asimétricas de dominación y subordinación, tales como el colonialismo, la esclavitud [...].” (PRATT, 2010, p. 31). De acordo com Mary Louise Pratt, as zonas de contacto constituem espaços sociais propícios para que as culturas originárias enunciem sua versão da história e construam sua identidade, pois

\begin{abstract}
La zona de contacto desplaza el centro de gravedad y el punto de vista hacia el espacio y el tempo del encuentro, al lugar y al momento en que individuos que estuvieron separados por la geografía y la historia ahora coexisten en un punto, el punto en que sus respectivas trayectorias se cruzan [...] los individuos que están en esta situación se constituyen en y a través de su relación mutua [...]. (PRATT, 2010, p. 34).
\end{abstract}

Os textos coloniais escritos por mestiços ou indígenas apresentam um relato oposto ao desenvolvido pelos cronistas europeus no que se refere à representação do indígena, e revelam uma versão pessoal e diferente da história desses povos. Conforme Pratt (2010, p. 3536), as obras citadas podem ser consideradas textos 'autoetnográficos', posto que neles “[...] los sujetos colonizados emprenden su propia representación de manera que se 'comprometen' con los términos del colonizador'. Levando em consideração que nos textos etnográficos os europeus representam para eles mesmos aos outros, Pratt acrescenta que os textos autoetográficos "[...] son los [textos] que los otros construyen para responder a esas representaciones metropolitanas y para dialogar con ellas.” Textos direcionados tanto aos leitores metropolitanos quanto aos leitores do próprio grupo social do escritor, que revelam "[...] relatos da dominación imperial y de la resistencia vistos desde el lugar mismo en que ocurrían." Trata-se nas palavras de José Antonio Mazzotti (1996, p. 20) de textos que surgiram “[...] como respuesta a diversas tendencias ideológicas manifestadas en las historias sobre el Nuevo Mundo en función de intereses propios de un sujeto colonial dominante."

Dentro desse contexto, a obra do Inca Garcilaso de la Vega pode ser considerada uma das primeiras fontes escritas por um mestiço que enfrentou a história oficial da conquista. 
O Inca Garcilaso participou ativamente na construção e narração de sua própria história, acabando com a posição secundária e passiva que lhe conferiam os cronistas espanhóis. Para escrever Comentarios Reales, o escritor mestiço se apoiou em fontes orais andinas, como, por exemplo, a voz de seu tio-avô materno, chamado pelo autor de Inca viejo: "Lo que yo digo lo oí al Inca viejo que contaba las antigüedades y fábulas de sus reyes en la presencia de mi madre." (GARCILASO DE LA VEGA, 2015a, Tomo II, p. 275). Nessa reconstrução da história do povo inca colaboraram também outros indígenas, como o registrou o próprio Inca Garcilaso em Comentarios Reales:

\begin{abstract}
Porque luego que propuse escribir esta historia, escribí a los condiscípulos de escuela y gramática encargándoles que cada uno me ayudase con la relación que pudiese haber de las particulares conquistas que los Incas hicieron de las provincias de sus madres, porque cada provincia tiene sus cuentas y nudos con sus historias anales y la tradición de ellas, y por esto retiene mejor lo que en ella pasó que lo que pasó en la ajena. Los condiscípulos, tomando de veras lo que les pedí, cada cual de ellos dio cuenta de mi intención a su madre y parientes, los cuales, sabiendo que un indio, hijo de su tierra, quería escribir los sucesos de ella, sacaron de sus archivos las relaciones que tenían de sus historias y me las enviaron, y así tuve la noticia de los hechos y conquistas de cada Inca, que es la misma que los historiadores españoles tuvieron, sino esta será más larga, como lo advertiremos en muchas partes de ella. (GARCILASO DE LA VEGA, 2015a, Tomo II, p. 54).
\end{abstract}

Os archivos aos que faz referência o Inca Garcilaso são os quipus ${ }^{1}$, documentos incaicos que contêm informações sobre a administração desse povo. Dessa maneira, o Inca ressignifica as fontes indígenas não alfabéticas diante da visão de mundo do espanhol. Portanto, as bases da obra do Inca estão ancoradas nos recursos orais proporcionados tanto pelos membros da família materna quanto por seus condiscípulos, assim como pelos quipus.

Para a concretização de Comentarios Reales o Inca Garcilaso utilizou diferentes estratégias retóricas com o objetivo de questionar as representações feitas sobre seu povo nas histórias oficiais, uma maneira de reescrever a história e propiciar um diálogo com os cronistas espanhóis, o que implicou uma "[...] cierta apropiación de los idiomas del conquistador: la escritura alfabética, la lengua española, la forma literária llamada crónica, el dibujo de línea, el papel." (PRATT, 2010, p. 36), assim sendo, ao se apropriar das estratégias do colonizador e de empegar táticas sutis para subverter o discurso colonial, o Inca Garcilaso, conseguiu reterritorializar o indígena que tinha sido privado não somente de sua terra e de seus direitos, senão também de sua própria história.

Considerando que as fontes incaicas utilizadas pelo Inca Garcilaso eram

\footnotetext{
${ }^{1}$ Quipo (do quíchua cusquenho Quipo ou Khipu, "nó") era um instrumento utilizado para comunicação, mas também como registro contábil e como registros mnemotécnicos entre os incas. Eram feitos da união de cordões que podem ser coloridos ou não, e poderia ter enfeites, como por exemplo ossos e penas, em que cada nó que se dava em cada cordão significava uma mensagem distinta.
} 
fundamentalmente orais Mazzotti destaca que na passagem dessa oralidade para a escrita ocorreu um "entrecruzamento discursivo" em que os processos de transculturação encontraram uma "[...] materialización inicial en forma discursiva” (MAZZOTTI, 1996, p. 324). O crítico acrescenta que o produto resultante desse entrecuzamento discursivo apresenta interferências que "[...] es posible rastrear y describir en aquellos textos que tienen una fuente oral andina evidente, sirven para presentar la pauta de un producto verbal." (MAZZOTTI, 1996, p. 326) e, explica que esas interferências ocorrem nos diferentes níveis da linguagem da "escritura coral" pois nela "[...] las voces narrativas se multiplican y superponen de manera que llega a hacerse por momentos muy difícil distinguir cuál es la fuente inmediata de determinados discursos al interior de la obra [...]." (MAZZOTTI, 1996, p. 324).

Para explicar em que consiste a "escritura coral" Mazzotti destaca caraterísticas da tradição discursiva cuzqueña. Começa lembrando que era costume dentro da tradição incaica que o Inca que assumia o poder encomendara a cantores populares a composição da "[...] historia de sus ancestros a fin de exaltar los méritos y hazañas de su grupo familiar y de los gobernantes anteriores vinculados a él." (MAZZOTTI, 1996, p. 31). Um sistema de registro histórico oral que serviu de base para a configuração de textos andinos escritos durante o período colonial, como, por exemplo, Relación de la descendencia, gobierno y conquista de los incas ${ }^{2}$ [1542], escrito pelos historiadores indígenas oficiais ou khipukamayuq para o governador Vaca de Castro; Suma y narración de los incas ${ }^{3}$ [1548-1556] do explorador e cronista espanhol Juan Diez de Betánzos e Instucción del Inca don Diego de Castro Titu Cusi Yupanqui al Licenciado don Lope García de Castro, escrito por Titu Cusi Yupanqui em 1570. Textos que apresentam “[...] puntos de contacto entre el relato histórico cuzqueño que les sirvió de fuente y el español escrito en el que nos presentan, con todas las interpolaciones, adiciones y omisiones que ello implica." (MAZZOTTI, 1996, p. 33).

Mazzotti destaca que na configuração dos três textos citados os autores podem ter utilizado como base de informação os 'cantares históricos' indígenas, assim como outros registros não necessariamente orais, originando um texto que resulta de "dos sistemas (el cuzqueño y el peninsular) de narración histórica." (MAZZOTTI, 1996, p. 33). Uma escrita bicultural em que a oralidade indígena é transcrita em espanhol e não em quéchua, trata-se, portanto, de um discurso que oscila entre a tradição espanhola e a tradição cuzqueña que

\footnotetext{
${ }^{2}$ Também conhecido como Relación... de los khipukamayuq ao governador Vaca de Castro.

${ }^{3}$ Considerada a primeira obra indigenista que narra a história das culturas andinas e o encontro com os espanhóis. A narração foi feita a partir do testemunho oral de anciãos andinos. Juan de Betánzos, casou-se com a esposa principal de Atahualpa.
}

Anu. Lit., Florianópolis, v. 23, n. 1, p. 87-98, 2018. ISSNe 2175-7917 
recebe o nome de escritura coral, denominação que deriva das fontes incas das que se origina. Dessa maneira, a escrita coral é concebida por Mazzotti (1996, p. 34) como um tipo específico de polifonia, como uma "conversión de las voces del relato en discursos significativos propios y autónomos en tanto ideología y concepción de mundo [...] que [...] supondrá el rastreo de marcas verbales que provienen o imitan una tradición discursiva cortesana cuzqueña [...]."

De acordo com o anterior, pode-se afirmar que em Comentarios Reales o Inca Garcilaso desenvolveu uma obra bicultural que questiona a maneira inca de preservar "la memoria de las cosas pasadas", como pode ser constatado no fragmento a seguir:

\begin{abstract}
- Inca, tío, pues no hay escritura entre vosotros, que es lo que guarda la memoria de las cosas pasadas ¿qué noticias tenéis del origen y principio de nuestros Reyes? Porque allá los españoles y las otras naciones, sus comarcanas, como tienen historias divinas y humanas, saben por ellas cuándo empezaron a reinar sus Reyes y los ajenos y al trocarse unos imperios en otros, hasta saber cuántos mil años hay que Dios creó el cielo y la tierra - que todo esto y mucho más saben por sus libros. Empero vosotros, que carecéis de ellos, ¿qué memoria tenéis de vuestras antiguallas?, iquién fue el primero de nuestros incas?, ¿cómo se llamó? [...]. (GARCILASO DE LA VEGA, 2015a, Tomo II, p. 46).
\end{abstract}

A partir do questionamento apresentado podemos afirmar que o Inca Garcilaso desenvolveu de forma conscientemente um projeto retórico que objetivava outorgar ao discurso oral andino o mesmo valor do texto historiográfico europeu. Esse projeto retórico constitui sua obra maior e consta de duas partes, a saber: a primeira parte intitulada Comentarios Reales de los Incas [1616] e a segunda parte intitulada Historia general del Perú [1617]. No Prólogo à segunda parte de Comentarios Reales o Inca Garcilaso explica o motivo que o levou a escrever sua obra,

[...] señores y hermanos míos, escribí la primera y escribo la segunda parte de Comentarios Reales [...] La primera, para dar a conocer al universo nuestra patria, gente y nación [...] dando cuenta de las gloriosas empresas de los incas [...] El segundo respeto y motivo de escribir esta historia fue celebrar las grandezas de los heroicos españoles [...]. (GARCILASO DE LA VEGA, 2015b, Tomo III, p. 12-14).

No entanto, cabe destacar neste momento a epígrafe que abre este texto, no qual percebe-se a intenção reivindicadora e revisionista do escritor mestiço, pois não se trata somente de "dar a conocer" a história dos incas e a dos espanhóis, senão de questionar o discurso desenvolvido pelos europeus sobre o "Novo Mundo",

Habiendo de tratar del nuevo mundo parece que fuera justo, conforme a la común costumbre de los escritores, tratar aquí al principio, si el mundo es uno solo o si hay muchos mundos. [...] que no hay más que un mundo. Y aunque llamamos 'mundo viejo' y 'mundo nuevo' es por haberse descubierto aquel nuevamente para nosotros y no porque sean dos, sino todo uno. (GARCILASO DE LA VEGA, 2015a, Tomo 
II, p. 19).

Para o Inca Garcilaso a compreensão de um mundo uno é resultado de sua trajetória de vida, de seu trânsito entre a colônia e a metrópole, é a visão de mundo do novo homem americano que questiona e reescreve sua história. Um escritor colonial que para alcançar seu objetivo reivindicador utilizou diversas estratégias discursivas.

Homi K. Bhabha en O local da cultura (2013), apresenta estratégias utilizadas pelo sujeito colonial para contestar a história escrita pelos colonizadores. Na obra do Inca Garcilaso podem ser identificadas algumas das estratégias destacadas por Bhabha como, por exemplo, a "mímica ou apropriação" e a "civilidade dissimulada". Para o crítico indiano a mímica seria o desejo do poder colonial de transformar o sujeito colonial numa entidade que incorpore suas próprias características, ainda que não totalmente, pois isso representaria a conquista e conversão total do povo dominado, reafirmando, dessa maneira, a imposição da cultura do colonizador na sociedade colonial. Conforme Bhabha (2013, p. 146):

[...] a mímica colonial é o desejo de um Outro reformado, reconhecível, como sujeito de uma diferença que é quase a mesma, mas não exatamente [...] A mímica é, assim, o signo de uma articulação dupla, uma estratégia complexa de reforma, regulação e disciplina que se "apropria" do Outro ao visualizar o poder [...] O efeito da mímica sobre a autoridade do discurso colonial é profundo e perturbador.

Desse modo, a reprodução dos valores do poder colonial pressupõe una ambivalência que transforma o sujeito colonial numa ameaça para o colonizador, pois, o Inca Garcilaso ao reproduzir a escrita europeia, com o intuito de retificar as imagens negativas da cultura indígena, desenvolve um tipo de mímica subversiva, que segundo Lacan:

[...] revela [a mímica] algo na medida em que é distinta do que poderia ser chamado um si-mesmo que está por trás. O efeito da mímica é a camuflagem ... Não se trata de se harmonizar com o fundo, mas contra um fundo mosqueado, ser também mosquedo - exatamente como a técnica da camuflagem praticada na guerra dos homens. (LACAN apud BHABHA, 2013, p. 145).

Contudo, pode considerar-se que a apropriação da linguagem do colonizador é a estratégia retórica mais importante empregada pelo Inca para restabelecer o indígena dentro do discurso histórico e, para falar da civilização Inca. Dessa maneira, a língua espanhola junto à língua materna, o quéchua, se transforma na ferramenta fundamental que garante o acesso ao passado andino. O Inca escreve em espanhol, mas também apresenta de forma detalhada as caraterísticas de sua língua materna, como se pode observar na transcrição a seguir:

[...] Entre otros templos famosos que en el Perú había dedicados al sol [...] hubo uno en la isla llamada Titicaca, que quiere decir sierra de plomo; [...] hanse de pronunciar ambas sílabas $\mathrm{Caca}$ en lo interior de la garganta, porque pronunciadas 
como suenan las letras españolas quiere decir tío, hermano de madre. (GARCILASO DE LA VEGA, 2015a, Tomo II, p. 178).

Além de explicar os tempos gramaticais e o significado das palavras, o Inca Garcilaso dedica especial atenção à pronunciação das vogais, pondo dessa maneira o quéchua em pé de igualdade com a língua escrita, pois em Comentarios Reales "como en ninguna obra de su género, está presente, como un hilo conductor de todo el discurso garcilasiano, la disquisición lingüistica como parte inescapable de la argumentación histórica." (CERRÓNPALOMINO, 1995, p. 192). Logo, ao dedicar todo um capítulo às regras linguísticas do quéchua, o Inca restabelece a importância que tinha esse idioma antes da chegada dos europeus, posto que, segundo o Inca era necessário apresentar as regras e explicações linguísticas porque os espanhóis tinham corrompido o quéchua:

\begin{abstract}
Para atajar esta corrupción me sea lícito, porque soy indio, que en esta historia yo escriba como indio con las mismas letras que aquellas tales dicciones se deben escribir; y no se les haga mal a los que las leyeren ver la novedad presente en contra de mal uso introducido [...] Y porque me conviene alegar muchas cosas de las que dicen los historiadores españoles para comprobar las que yo fuere diciendo, y porque las he de sacar a la letra con su corrupción como ellos las escriben, quiero advertir que no parezca que me contradigo escribiendo las letras, que he dicho, que no tiene aquel lenguaje, que no lo hago sino por sacar fielmente lo que el español escribe. (GARCILASO DE LA VEGA, 2015a, Tomo II, p. 17)
\end{abstract}

Constata-se dessa maneira que para o Inca o conhecimento direto da língua possibilitava o acesso à verdade histórica na reconstrução do passado. Cabe destacar que além da preocupação linguística o Inca sente a obrigação de escrever sua história porque entende que não se pode aceitar nenhuma história como 'história completa' até que não se inclua a voz do 'outro'. Dessa maneira, a mímica ou apropriação resulta uma estratégia retórica magistral para desafiar a autoridade tanto discursiva quanto política do poder colonial. Nas palavras de Bhabha (2013, p.150): “A ameaça da mímica é sua visão dupla que, ao revelar a ambivalência do discurso colonial, também desestabiliza sua autoridade. É uma visão dupla que é o resultado do que descrevi como representação/reconhecimento parcial do objeto colonial."

Essa "visão dupla" de que nos fala Bhabha concretiza-se em Comentarios Reales, pois é uma obra na que a história depende da oralidade: uma obra escrita em espanhol, na que se empregaram os recursos da tradição europeia, mas que procede de uma cultura oral, o que configura o resgate da verdade por meio da análise da língua originária. Assim, por ser de natureza oral o texto originário sobre o qual se baseia, Garcilaso teve que centrar sua atenção em certos termos chave que provocaram confusão e erros de compreensão para os espanhóis.

No Prólogo à Historia General del Perú [1617], segunda parte de Comentarios Reales, o Inca compara a civilização inca à espanhola antiga, considerada uma civilização 
'bárbara' pelos gregos e latinos:

De la suerte que antiguamente los griegos y romanos, por ser nata y flor del saber y poder, a las demás regiones en comparación suya llamaban bárbaras; entrando en esta cuenta la española, no por serlo de su natural, mas por faltarle lo artificial; pues luego con el Arte dio Naturaleza muestras heroicas de ingenio de letras [...]; ya levanta la cabeza entre sus émulas naciones [...] antes inculta, hoy por tu medio cultivada, y de bosque de gentilidad e idolatría, vuelta en paraíso de Cristo. (GARCILASO DE LA VEGA, 2015b, Tomo III, p. 13)

Estratégia retórica que lhe permite comparar a evolução do império Inca ao da Espanha, e afirmar, que há muito pouca diferença entre as duas civilizações, mas o propósito do Inca Garcilaso não é afirmar as semelhanças, senão criticar o poder colonial, e isso e feito quando narra de forma detalha a maneira de conquistar, as estruturas social e administrativa dos incas, assim como seu desenvolvimento científico, tecnológico e literário. Mas o Inca incorpora essas informações a seu relato de forma sutil, procedimento que reafirma a importância da mímica como una estratégia para subverter o discurso hegemônico, posto que a mímica, nas palavras de Bhabha (2013, p. 153-154) é:

[...] o processo de fixação do indivíduo colonial como forma de saber transclassificatorio, discriminatório no interior de um discurso de interdição, e, portanto, levanta obrigatoriamente a questão da legitimação das representações coloniais [...] Sob o disfarce da camuflagem, a mimica como o fetiche, é um objeto parcial que radicalmente reavalia os saberes normativos da prioridade da raça, da escrita e da história, pois o fetiche imita as formas de autoridade ao mesmo tempo que as desautoriza.

Outra estratégia destacada por Bhabha é a 'civilidade dissimulada', conceito a partir do qual discute como o nativo resiste à imposição de uma religião e de uma cultura estranha por parte do poder colonial. A denominada 'civilidade dissimulada' é uma atividade que supõe a cooperação do nativo no processo de reforma do sujeito colonial para que aceite e atue de acordo com os códigos do sistema metropolitano. Processo discursivo que pode ser observado ao longo da conquista e colonização da América, quando o poder imperial exigia que tanto os conquistadores quanto os cronistas relatassem tudo o que acontecia no "Novo Mundo". Para alcançar tais objetivos os cronistas solicitavam a colaboração do indígena. Fato conhecido é o do missionário franciscano Bernardino de Sahagún (1499-1590) que recorreu às informações proporcionadas pelos indígenas quando escreveu La Historia General de las cosas de Nueva España (1540-1585). O libro se configura a partir dos registros de conversações e entrevistas realizadas a indígenas de Tlatelolco, Texcoco e Tenochtitlán.

Mas, o propósito de Sahagún não era dar voz aos indígenas, e sim dar a conhecer entre seus colegas missionários aspectos da cultura e da história indígena, informações que 
serviriam como ferramentas evangelizadoras, por meio das quais compreenderiam o pensamento indígena, possibilitando assim, a persuasão de um maior número de adeptos:

[...] puesto que los predicadores y confesores médicos son de las almas, para curar las enfermedades espirituales conviene que tengan experiencia de las medicinas y de las enfermedades espirituales: el predicador, de los vicios de la religión [mesoamericana] para enderezar contra ellos su doctrina, y el confesor para saber preguntar lo que conviene, y saber entender lo que dijeron tocante a su oficio. Para predicar contra esas cosas, y aun para saber si las hay, es menester saber cómo las usaban [los indígenas] en tiempo de su idolatría. (SAHAGÚN, 1938, p. 27-28).

Contudo, como bem registra Bhabha o sujeito colonial atua com "civilidade dissimulada" no lugar de colaborar:

A incerteza gerada por aquela resistência transforma a própria demanda narrativa. $\mathrm{O}$ que era falado dentro das ordens da civilidade agora acede ao significante colonial. A questão não e mais "Conte tudo exatamente como se passou" de Derrida. Do ponto de vista do colonizador, apaixonado pela posse ilimitada, despovoada, o problema da verdade se transforma na difícil questão política e psíquica de limite e território: Digam-nos por que vocês, os nativos, estão ai. (BHABHA, 2013, p. 166).

Quando o Inca Garcilaso narra sua versão da história passa a impressão de que está colaborando com o poder colonial, mas o que realmente faz é subverter o projeto de subordinação do povo autóctone. Trata-se da prática da civilidade dissimulada destacada por Bhabha, em que por trás dessa civilidade dissimulada se esconde outro objetivo: o de apresentar a sua versão da história, como o próprio Garcilaso o registra no Proemio ao Lector:

Aunque ha habido españoles curiosos que han escrito las repúblicas del Nuevo Mundo [...] Por lo cual, forzado del amor natural a la patria me ofrecí al trabajo de escribir estos Comentarios [...] En el discurso de la historia protestamos la verdad de ella, no diremos cosa grande, que no sea autorizándola con los mismos historiadores españoles que la tocaron en parte o en todo: que mi intención no es contradecirles, sino servirles de comento y glosa, de intérprete en muchos vocablos indios, que como extranjeros en aquella lengua interpretaron fuera de la propiedad de ella. (GARCILASO DE LA VEGA, 2015a, Tomo II, p. 6).

Dessa maneira, contradiz de forma sutil as palavras de cronistas e historiadores sobre os indígenas, sua cultura e sua civilização, trata-se, segundo González Echevarría (2011, p. $83-84)$ de

[...] una tarea revisionista, pues al escribir desde su punto de vista dual de indio y europeo, Garcilaso ofrecía una narración dramática de la historia de América que no sólo contaba el relato, sino que también reflexionaba sobre la manera de contarlo [...] cómo un individuo con raíces en el Nuevo Mundo podía contar su propia historia.

Pode-se destacar também a representação apresentada pelo escritor mestiço sobre como os Incas realizaram a conquista dos povos andinos, uma crítica implícita à conquista e 
ao processo de colonização dos espanhóis. Mas, no lugar de criticar explicitamente o caráter violento da conquista espanhola, o Inca só descreve a maneira como o poder imperial incaico conquistava e colonizava a outros povos, destacando dessa maneira a brutalidade da invasão europeia:

\begin{abstract}
El Inca Manco Capac, yendo poblando juntamente con enseñar a cultivar la tierra a sus vasallos y labrar las casas, y sacar acequias y hacer las demás cosas necesarias para la vida humana, les iba instruyendo en la urbanidad, compañía y hermandad, que unos a otros se habían de hacer, conforme a lo que la razón y ley natural les enseñaba, persuadiéndoles con mucha eficacia, que para que entre ellos hubiese perpetua paz y concordia y no naciesen enojos y pasiones, hiciesen con todos lo que quisieran que todos hicieran con ellos; porque no se permitía querer una ley para sí y otra para los otros. (GARCILASO DE LA VEGA, 2015a, Tomo II, p. 57).
\end{abstract}

Cabe lembrar que tanto na Idade Média quanto no Renascimento existia um sistema rígido que regulamentava a escrita,

[...] escribir no se concebía como una acción mediante la cual una conciencia desnuda, enfrentada a un fenómeno empírico o espiritual nuevo, expresa su reacción [...] En aquel entonces, escribir era una tarea que se realizaba conforme un sistema de reglas y fórmulas estrictas que comprendía lo que em grandes rasgos podría llamarse retórica. (GONZÁLEZ ECHEVARRÍA, 2011, p. 81)

Pelo que o Inca Garcilaso teve que se ater a uma série de regras retóricas para reescrever a História de seu povo, motivo pelo qual fez uso de recursos retóricos, como, por exemplo, a 'falsa modéstia', pois ao se referir a sua obra como "mi pobre historia" (GARCILASO DE LA VEGA, 2015a, Tomo II, p. 125) ou ao se autodefinir como 'pobre índio', imita o desprezo dos cronistas e historiadores do discurso hegemônico. Pelo que o Inca consciente de que o poder imperial reprimiria qualquer indígena que quisesse apresentar a sua versão da história, destaca a todo momento que ele escrevia como índio:

Los españoles añaden estas letras en perjuicio y corrupción del lenguaje, y, como los indios no las tienen, comúnmente pronuncian mal las dicciones españolas que las tienen. Para atajar esta corrupción me sea lícito, pues soy indio, que en esta historia yo escriba como indio con las mismas letras que aquellas tales dicciones se deben escribir. (GARCILASO DE LA VEGA, 2015a, Tomo II, p. 17).

E enfatiza que sua obra era una 'pobre historia': "Esto puse aqui por enriquecer mi pobre historia. Porque, cierto, sin lisonja alguna, se puede decir que todo lo que el Padre Blas Valera tenía escrito eran perlas y piedras preciosas: no mereció mi tierra verse adornada de ellas." (GARCILASO DE LA VEGA, 2015a, Tomo II, p. 125). Devido ao teor da obra do Inca Garcilaso o crítico peruano Alberto Escobar (1960, p. XVI) considera a prosa do escritor mestiço: "[...] sencilla, harmoniosa, equilibrada. Como si en ella se sellara el 
futuro destino de la literatura peruana: hacer del español el instrumento hábil para comunicar las pasiones y esperanzas de un pueblo mestizo."

Conclui-se, então, que em Comentarios Reales I e II as estratégias discursivas de resistência utilizadas pelo Inca Garcilaso subvertem o controle colonial e dessa maneira o indígena adquire uma dimensão histórica como sujeito ativo, negando a posição secundária e passiva que lhe conferiam os cronistas espanhóis. O Inca utiliza as fontes orais andinas para escrever sua história e recuperar a memória de seu povo.

\section{Referências}

BHABHA, Homi K. O local da cultura. Trad. de Myriam Ávila; Eliana Lourenço de Lima Reis; Gláucia Renate Gonçalves. 2. ed. Belo Horizonte: UFMG, 2013.

BLIXEN, Hyalmar. El Inca Garcilaso de la Vega y sus comentarios reales. Diario Lea. Montevideo, 15 de enero de 1990. Disponível em: <http://letrasuruguay.espaciolatino.com/blixen_hyalmar/inca_garcilaso_de_la_vega.htm $>$. Acesso em: 05/06/2016.

CERRÓN PALOMINO, Rodolfo. Los fragmentos de gramática quechua del Inca Garcilaso. Actes: La "découverte" des langues et des écritures d'Amérique. 1995. v. 19/20. p. 191-202. Disponível em: <https://www.vjf.cnrs.fr/sedyl/amerindia/articles/pdf/A_19-20_16.pdf $>$. Acesso em: 15/05/2016.

ESCOBAR, Alberto. La narración en Perú. Estudio preliminar y antología y notas. Lima: Librería Editorial Juan Mejía Baca, 1960.

GARCILASO DE LA VEGA, Inca. Comentarios Reales. Tomo II. Obras Completas. Edición y Notas Carlos Araníbar. Lima: Ministerio de Relaciones Exteriores del Perú, 2015a.

GARCILASO DE LA VEGA, Inca. Historia General del Perú. Tomo III. Obras Completas. Edición y Notas de Carlos Araníbar. Lima: Ministerio de Relaciones Exteriores del Perú, $2015 b$.

GONZÁLEZ ECHEVARRÍA, Roberto. Mito y archivo: uma teoría de la narrativa latinoamericana. Trad. de Virginia Aguirre Muñoz. 2. ed. México: F.C.E, 2011.

PRATT, Mary Luise. Ojos Imperiales: literatura de viajes y transculturación. Trad. de Ofelia Castillo. México: FCE, 2010.

MAZZOTTI, José Antonio. Coros mestizos del Inca Garcilaso de la Vega: resonancias andinas. México: Bolsa de Valores de Lima, F.C.E, 1996.

SAHAGÚN, Bernardino de. Historia general de las cosas de la Nueva España. Edição de Joaquín Ramírez Cabañas, 5 v. México: Editorial de Pedro Robredo, 1938. 
The Inca Garcilaso de la Vega and the transition between colony and metropolis: historical and literary revisionism

Abstract: The firsts colonial texts of indigenous and mestizo authorship were published in Hispanic América during XVII century. First published book was titled Comentarios Reales (1609) written by Peruvian writer Inca Garcilaso de la Vega (1539-1616), in 1615 it was published Nueva corónica y buen gobierno by the indigenous chronicler Felipe Guaman Poma de Ayala (1534-1615). These works are an important part of the colonial literary corpus, since they were backgrounded at the contact zones. (Pratt, 2010, p.31). These colonial texts written by mestizos or natives present an opposite point of view vis a vis the one reflected by European chroniclers regarding representation of the native life and costumes, and reveal a personal and alternative angle of those people lives. Within this context, the work of the Inca Garcilaso de la Vega can be considered one of the first sources written by a mestizo that opposed the official history of the conquest. The Inca Garcilaso participated actively in the construction and narration of his own history, ending with the peripherical and passive position that the Spanish chroniclers gave him.

Keywords: Postcolonial literature. Historical revisionism. Cultural decolonization.

Recebido em: 13/07/2017

Aceito em: 02/03/2018

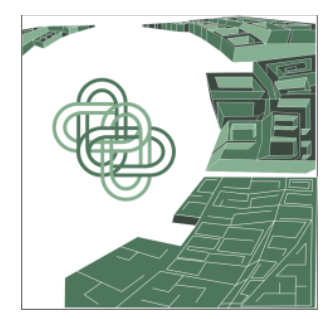

